\title{
Does euthyroid mean healthy? Effect of restoration of thyroid function on body composition, insulin resistance and visfatin concentrations in women with hypo- and hyperthyroidism.
}

Nadia Sawicka-Gutaj ( $\nabla$ nsawicka@ump.edu.pl )

Uniwersytet Medyczny imienia Karola Marcinkowskiego w Poznaniu

Ariadna Zybek-Kocik

Poznan Univeristy of Medical Sciences

Michał Kloska

Lehigh Valley Health Network, Department of Medicine, USA

Agata Czarnywojtek

Department of Pharmacology

Paulina Ziolkowska

Department of Endocrinology

Jerzy Sowiński

Department of Endocrinology

Dorota Mańkowska-Wierzbicka

Department of Gastroenterology

Marek Ruchala

Department of Endocrinology

\section{Research}

Keywords: Hashimoto's disease, Graves' disease, nicotinamide phosphoribosyltransferase, pre-B-cell colony enhancing factor, fat tissue

Posted Date: May 4th, 2020

DOl: https://doi.org/10.21203/rs.3.rs-25942/v1

License: (9) (1) This work is licensed under a Creative Commons Attribution 4.0 International License. Read Full License 


\section{Abstract \\ Background}

We aimed to investigate the effect of restoration of euthyroidism on serum visfatin in severe thyroid dysfunction, and its associations with insulin resistance and body composition.

\section{Methods}

This was an observational study with consecutive enrollment. We included females newly diagnosed with overt hypo- or hyperthyroidism caused by autoimmune thyroid diseases. Laboratory parameters and body composition analysis were assessed before and after the therapy.

\section{Results}

Initially, 105 females were enrolled: 49 hyperthyroid (median age of 34 years) and 44 hypothyroid (median age of 46) completed the study. In the hyperthyroid group, visfatin levels increased $(<0.0001)$, while glucose levels decreased ( $<0.0001)$. Total body mass and fat mass in the trunk and limbs significantly increased during the treatment. In the hypothyroid group, significant weight loss resulted from decrease of fat and muscle masses in trunk and limbs. Visfatin serum concentrations positively correlated with total fat mass $(r=0.19, p=0.01)$ and insulin levels $(r=0.17, p=0.0 .18)$.

\section{Conclusions}

We may conclude that restoration of thyroid function is not associated with beneficial changes in body composition, especially among hyperthyroid females, reflected by the significant increase of fat mass followed by the increase of circulating visfatin concentrations.

\section{Background}

The adipose tissue is a well-established source of multiple circulating peptides that are responsible for various metabolic effects (1). Visfatin, cytokine secreted mainly by adipose tissue, has been extensively investigated within the past decade in different pathologies including metabolic disorders, neoplasms, and inflammatory conditions. Thyroid hormones also profoundly affect thermogenesis, metabolic rate, food intake and energy expenditure. Thus, both hypo- and hyperthyroidism significantly alter these processes, resulting in body composition changes reflected by clinical signs and symptoms $(2,3)$. Moreover, concomitant chronic inflammation causing thyroid disorders, independently of thyroid hormones, may have systemic effects $(4,5)$. 
We have recently found visfatin/NAMPT overexpression in thyroid cancers and in thyroid glands of patients with Graves' orbitopathy, as well as in their leukocytes, supporting anti-apoptotic and proinflammatory properties of this adipocytokine (6-8). However, previous studies on changes in visfatin serum levels in different thyroid dysfunctions brought inconclusive results, what might be partially explained by the heterogenous etiology of thyroid disorders (9-13). We already reported that visfatin serum concentration in hypothyroidism is associated with free thyroid hormones and antithyroperoxidase antibodies, while in hyperthyroidism visfatin mainly correlates with fat content with minor effect of thyroid autoimmunity $(14,15)$.

Therefore, we aimed to investigate the effect of restoration of euthyroidism on serum visfatin in severe thyroid dysfunction, and its associations with insulin resistance and body composition. To limit the interference of individual factors, we have also analysed changes in three different thyrometabolic states in the same patients.

\section{Patients And Methods}

\section{Study design and patient enrollment}

This was an observational study with consecutive enrollment. We included females newly diagnosed with overt hypo- or hyperthyroidism caused by autoimmune thyroid diseases (Hashimoto's disease or Graves' disease, respectively). The diagnoses of hyper- and hypothyroidism, as well as Graves' or Hashimoto's disease were made according to current recommendations, and were based on physical and biochemical examination. All patients were subsequently treated according to guideline-based therapy: patients with hyperthyroidism received methimazole and some of them were treated with radioiodine (RAI). These females who developed hypothyroidism following RAl administration and patients with Hashimoto's disease became euthyroid on levothyroxine substitution. Exclusion criteria were: other acute or chronic diseases including autoimmune diseases and/or infections and any other medications taken on regular basis (potentially affecting body composition or visfatin concentrations). The study was approved by the local Ethical Committee and all patients signed an informed consent.

\section{Laboratory measurements}

Serum concentrations of visfatin, TSH, FT4, FT3, anti-thyroperoxidase antibodies (TPOAbs), fasting glucose and insulin were measured in a consecutive manner in each patient before and after restoration of thyroid function. Thyrotropin receptor antibodies (TRAbs) were assessed in the hyperthyroid group before the onset of therapy and when the euthyroidism was anticipated. ELISA Assay Kit from Phoenix Pharmaceuticals was used to assess visfatin levels. Electrochemiluminescence technique was applied for estimation of TSH, FT4, FT3 concentrations (normal ranges: TSH 0.27-4.2 mU/l; FT4 11.5$21.0 \mathrm{pmol} / \mathrm{l} ; \mathrm{FT} 3$ 3.9-6.7 pmol/l). TRAb titers were measured with the use of radioimmunoassay TRAK Human Brahms (normal < 2 IU/I). TPOAb was assessed by radioimmunoassay (normal ranges: $<34 \mathrm{IU} / \mathrm{ml}$ ). Glucose levels were estimated using Hitachi Cobas e601 chemiluminescent analyzer (Roche Diagnostics) and insulin concentration was assessed using ELISA kit from Phoenix Pharmaceuticals. 
HOMA-IR was calculated to estimate insulin resistance. All patients were assessed before and after the therapy. In addition, hyperthyroid females who received RAI were assessed in hypothyroid state.

\section{Body composition analysis}

Body composition measurements were performed with the total body bioimpedance analyzer Tanita MC 180 MA II (Tanita, Japan) in all patients before and after restoration of thyroid function. Similar to laboratory assessment, body composition in hyperthyroid females treated with RAl was also performed in hypothyroid state.

\section{Statistical analysis}

Statistical analysis was performed with MedCalc Statistical Software version 18.10 (MedCalc Software bvba, Ostend, Belgium; http://www.medcalc.org; 2018). Normality was analyzed by the D’AgostinoPearson test. Since data did not follow normal distribution, comparison of the analyzed parameters within groups before and after restoration of thyroid function was performed using the nonparametric Wilcoxon test for paired data. Changes of analyzed parameters in the hyperthyroid, hypothyroid and euthyroid state were investigated with the non-parametric Friedman test with the post hoc multiple comparison tests. Comparison of results between hyper- and hypothyroid women was performed with the Mann-Whitney test. Spearman rank test was applied to find correlations between analyzed parameters. $\mathrm{P}$ value $<0.05$ was considered statistically significant.

\section{Results}

Initially, 105 females were enrolled into the study: fifty two with newly diagnosed hyperthyroidism in a course of Graves' disease and fifty three with naïve hypothyroidism caused by Hashimoto thyroiditis. Twelve women were lost to follow-up. Forty nine hyperthyroid females with a median age of 34 years (25th -75th percentile: 25-48 years) and forty four hypothyroid females with a median age of 46 years (25th -75th percentile: 33-52 years) achieved euthyroidism and completed the study. A median observation time was 9 months (25th -75th percentile: 8-10 months) in hyperthyroid group, and 6 months (25th -75th percentile: 5-7 months) in hypothyroid group. Fifteen hyperthyroid women developed hypothyroidism after RAI therapy, and underwent additional analysis in hypothyroid state.

\section{Effects of therapy on hormonal and metabolic status}

Hormonal and metabolic parameters are compared in Table 1.

\section{Hyperthyroid women}

TSH concentrations significantly increased and free thyroid hormones levels decreased after the therapy. The lowering of glucose levels after restoration of thyroid function was noted, while insulin concentrations remained unaltered. Visfatin concentrations increased when euthyroidism was achieved. We have not observed any associations between visfatin and other biochemical parameters. 


\section{Hypothyroid women}

TSH and TPOAbs concentrations decreased, while free thyroid hormones increased significantly after the therapy. Glucose and insulin levels, as well as visfatin did not change. Visfatin serum concentrations positively correlated with TPOAbs in both hypo- and euthyroid subjects $(r=0.535, p=0.0002 ; r=0.0026, p$ $=0.0026$, respectively). In euthyroid patients, visfatin negatively correlated with FT3 $(r=-0.372 ; p=0.0141)$.

Table 1

Changes of biochemical parameters in the study groups before and after restoration of thyroid function

\begin{tabular}{|c|c|c|c|c|c|c|}
\hline \multicolumn{4}{|c|}{ HYPERTHYROIDISM } & \multicolumn{3}{|c|}{ HYPOTHYROIDISM } \\
\hline $\begin{array}{l}\text { Median } \\
(25 \%-75 \%)\end{array}$ & Before & After & $P$ & Before & After & $\mathrm{p}$ \\
\hline 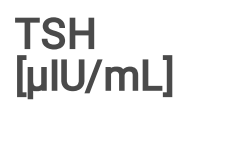 & $0.01(0.0-0.1)$ & $\begin{array}{l}1.45(0.98- \\
2.4)\end{array}$ & $\begin{array}{l}<.0001 \\
0.00\end{array}$ & $\begin{array}{l}81.6 \\
(55.8-100)\end{array}$ & $\begin{array}{l}1.6 \\
(1-2.3)\end{array}$ & $\begin{array}{l}< \\
0.0001\end{array}$ \\
\hline $\begin{array}{l}\text { FT4 } \\
\text { [pmol/L] }\end{array}$ & $\begin{array}{l}60.6(35.4- \\
86.6)\end{array}$ & $\begin{array}{l}16.7(14.9- \\
18.9)\end{array}$ & $\begin{array}{l}< \\
0.0001\end{array}$ & $\begin{array}{l}2.33(1.5- \\
3.8)\end{array}$ & $\begin{array}{l}16.7(15.3- \\
19.7)\end{array}$ & $\begin{array}{l}<.0001 \\
0\end{array}$ \\
\hline $\begin{array}{l}\text { FT3 } \\
\text { [pmol/L] }\end{array}$ & $\begin{array}{l}24.4(16- \\
32.4)\end{array}$ & $4.4(4-5.1)$ & $\begin{array}{l}< \\
0.0001\end{array}$ & $\begin{array}{l}0.94(0.7- \\
1.6)\end{array}$ & $5.0(4.2-5.8)$ & $\begin{array}{l}<.0001 \\
0 .\end{array}$ \\
\hline $\begin{array}{l}\text { glucose } \\
{[\mathrm{mg} / \mathrm{dl}]}\end{array}$ & $97(90-101)$ & $88(86-95)$ & $\hat{0} .0001$ & $89(83-97)$ & $90(85-96)$ & 0.60 \\
\hline $\begin{array}{l}\text { Insulin } \\
\text { [mU/ml] }\end{array}$ & $\begin{array}{l}9.3(5.8- \\
15.7)\end{array}$ & $\begin{array}{l}9.3(8.6- \\
11.5)\end{array}$ & 0.60 & $6.7(4.6-8.9)$ & $6.8(5.3-8.7)$ & 0.47 \\
\hline HOMA-IR & $2.3(1.4-4.1)$ & $2.0(1.7-2.7)$ & 0.13 & $1.42(1-2)$ & $1.5(1.1-1.9)$ & 0.64 \\
\hline $\begin{array}{l}\text { Visfatin } \\
\text { [ng/ml] }\end{array}$ & $\begin{array}{l}9.1(7.9- \\
11.4)\end{array}$ & $\begin{array}{l}12.3(9.9- \\
13.6)\end{array}$ & $\hat{0} .0001$ & $\begin{array}{l}9.32(8.50- \\
0.86)\end{array}$ & $\begin{array}{l}9.1(8.13- \\
11.21)\end{array}$ & 0.93 \\
\hline
\end{tabular}

TSH thyroid stimulating hormone; FT4 free thyroxine; FT3 free triiodothyronine

\section{Effects of therapy on body composition}

Results of body composition analyses are presented in Tables 2 and 3 .

\section{Hyperthyroid women}

Total body mass and fat mass significantly increased during the treatment. No significant change in total muscle mass was observed, while trunk muscle mass increased. Fat tissue increased in the trunk and limbs.

\section{Hypothyroid women}

Restoration of euthyroidism was associated with significant weight loss as a result of decrease of fat and muscle masses in trunk and limbs. 
Table 2

Changes of body composition in hypo- and hyperthyroid females before and after restoration of thyroid function

\begin{tabular}{|c|c|c|c|c|c|c|}
\hline \multicolumn{4}{|c|}{ HYPERTHYROIDISM } & \multicolumn{3}{|c|}{ HYPOTHYROIDISM } \\
\hline $\begin{array}{l}\text { Median } \\
(25 \%-75 \%)\end{array}$ & Before & After & $P$ & Before & After & $P$ \\
\hline $\begin{array}{l}\text { Body weight } \\
\text { [kg] }\end{array}$ & $\begin{array}{l}58.5(52.1- \\
68.5)\end{array}$ & $\begin{array}{l}63.4(58.5- \\
77.1)\end{array}$ & $\begin{array}{l}< \\
0.0001\end{array}$ & $\begin{array}{l}68.4(55.4- \\
69.6)\end{array}$ & $\begin{array}{l}64.7(59.2- \\
74.6)\end{array}$ & $\begin{array}{l}< \\
0.0001\end{array}$ \\
\hline FC [\%] & $\begin{array}{l}24.6(19.4- \\
28.8)\end{array}$ & $\begin{array}{l}28.9(24.4- \\
34.2)\end{array}$ & $\begin{array}{l}<.0001 \\
0.00\end{array}$ & $\begin{array}{l}28.9(25.4- \\
32)\end{array}$ & $\begin{array}{l}27(23.7- \\
30.8)\end{array}$ & 0.0001 \\
\hline FM [kg] & $\begin{array}{l}14.7(9.8- \\
21.6)\end{array}$ & $\begin{array}{l}18.6(14.9- \\
27.7)\end{array}$ & $\begin{array}{l}< \\
0.0001\end{array}$ & $\begin{array}{l}19.2(15.7- \\
23.2)\end{array}$ & $\begin{array}{l}16.4(13.9- \\
21.1)\end{array}$ & $\begin{array}{l}< \\
0.0001\end{array}$ \\
\hline FFM [kg] & $\begin{array}{l}43.9(40.5- \\
48.9)\end{array}$ & $\begin{array}{l}44.8(39.9- \\
49)\end{array}$ & 0.065 & $\begin{array}{l}47.3(43.5- \\
52.9)\end{array}$ & $\begin{array}{l}46.5(42.5- \\
50.4)\end{array}$ & $\begin{array}{l}< \\
0.0001\end{array}$ \\
\hline MM [kg] & $\begin{array}{l}42.3(39.3- \\
46.8)\end{array}$ & $\begin{array}{l}43.3(39.8- \\
47.9)\end{array}$ & 0.19 & $\begin{array}{l}44.6(41.3- \\
50.2)\end{array}$ & $\begin{array}{l}43.5(39.8- \\
47.8)\end{array}$ & $\hat{0}_{0.0001}$ \\
\hline
\end{tabular}

FC fat content; FM fat mass; FFM free fat mass; MM muscle mass

Table 3

Changes of fat and muscle distribution in hypo- and hyperthyroid females before and after restoration of thyroid function

\begin{tabular}{|c|c|c|c|c|c|c|}
\hline \multicolumn{4}{|c|}{ HYPERTHYROIDISM } & \multicolumn{3}{|c|}{ HYPOTHYROIDISM } \\
\hline $\begin{array}{l}\text { Median } \\
(25 \%-75 \%)\end{array}$ & Before & After & $\mathrm{P}$ & Before & After & $P$ \\
\hline $\begin{array}{l}\text { MM trunk } \\
{[\mathrm{kg}]}\end{array}$ & $\begin{array}{l}23.9(22- \\
26.9)\end{array}$ & $\begin{array}{l}25.6(23.4- \\
28.9)\end{array}$ & 0.007 & $26.4(24-29.7)$ & $\begin{array}{l}25.7(22.6- \\
27.9)\end{array}$ & 0.0001 \\
\hline \multirow{2}{*}{$\begin{array}{l}\text { MM limbs } \\
\text { [kg] }\end{array}$} & 18.0 & 18.1 & \multirow[t]{2}{*}{0.02} & \multirow{2}{*}{$\begin{array}{l}18.3(16.6- \\
20.9)\end{array}$} & \multirow{2}{*}{$\begin{array}{l}17.5(15.9- \\
19.5)\end{array}$} & \multirow[t]{2}{*}{0.0012} \\
\hline & $(16.6-20.7)$ & $(14.7-20.4)$ & & & & \\
\hline $\begin{array}{l}\text { FM trunk } \\
{[\mathrm{kg}]}\end{array}$ & $\begin{array}{l}6.8(4.8- \\
12.5)\end{array}$ & $9.2(7.1-15.3)$ & $\begin{array}{l}< \\
0.0001\end{array}$ & $9.7(7.3-12.2)$ & $9.0(5.5-11)$ & 0.0001 \\
\hline $\begin{array}{l}\text { FM limbs } \\
\text { [kg] }\end{array}$ & $\begin{array}{l}7.5(5.2- \\
10.1)\end{array}$ & $9.4(7-11.9)$ & $\begin{array}{l}<.0001 \\
0.000\end{array}$ & $8.8(7.6-11.9)$ & $8.5(6.8-11.3)$ & 0.0003 \\
\hline VFI & $3(1-6)$ & $4(2-6)$ & $<.0001$ & $5(3-6)$ & $4(2-6)$ & $\begin{array}{l}< \\
0.0001\end{array}$ \\
\hline
\end{tabular}

FM fat mass; MM muscle mass; VFI visceral fat index 
Hyperthyroid females had significantly lower body weight $(p=0.0034)$ and fat mass $(p=0.015)$ than hypothyroid females before the therapy was started, while muscle mass was similar at this time. When euthyroidism was reached, both groups did not differ with body weight, fat and muscle masses.

For pooled data of all women and all measurements, we found weak positive correlation between TSH concentrations and total body weight, as well as fat mass $(r=0.19, p=0.01 ; r=0.2, p=0.006$, respectively). There was also inverse correlation between FT4 and FT3 and total body weight $(r=-0.246, p$ $=0.0008 ; r=-0.17, p=0.022$, respectively $)$ and fat mass $(r=-0.16, p=0.026 ; r=-0.18, p=0.018$, respectively $)$. Muscle mass was associated neither with TSH nor thyroid hormones. Visfatin serum concentrations positively correlated with total fat mass $(r=0.19, p=0.01)$ and insulin levels $(r=0.17, p=0.0 .18)$, while there were no associations with body weight, fat trunk limb masses, muscle mass or TSH and free thyroid hormones.

Changes in visfatin concentration and body composition in three different thyrometabolic functional states in the same patients

We observed considerable increase in total body weight and visfatin concentrations in each patient, with the individual differences between hyperthyroidism, hypothyrodism, and euthyroidism $(p<0.0001)$

(Fig. 1a). The lowest fat mass was observed in hyperthyroid state $(p<0.0001)$ and it increased during the study (Fig. 1b). Although fat mass tended to decrease when females achieved euthyroidism, we did not find significant difference between hypothyroid and euthyroid states. In hypothyroidism, muscle mass decreased.

\section{Discussion}

We performed prospective study in women with severe thyroid dysfunctions of autoimmune origin, and we found that restoration of euthyroidism is associated with alterations in body composition. Hyperthyroid women gained weight, mainly due to increase of fat mass in trunk and limbs, while muscle mass remained unaltered. Significant increase of fat mass in hyperthyroid females was followed by the increase of visfatin concentration after the treatment. There is limited number of studies evaluating the changes in body composition during anti-thyroid therapy, especially taking into account an estimation of regional body mass distribution with a subdivision to limbs and trunk. Significant increase in fat mass during restoration of thyroid function was reported also by other authors (2). However, in contrast to our findings some studies described increase in muscle mass when euthyroidism was achieved $(2,16)$. What more, clinical improvement of muscle strength has been noted after restoration of thyroid function in subclinical and overt hyperthyroidism (16). Observed muscle weakness in hyperthyroid patients mainly results from changes in skeletal muscle metabolism with no muscle cells destruction, therefore posttherapeutic muscle mass might remain similar (17). We have performed a study solely among women, and similar influence of normalization of thyroid function on body composition parameters, including fat and muscle masses in Graves' hyperthyroidism has been recently reported by other authors (18). Weight loss in hypothyroid females in current study is a result of the decrease in both fat and muscle masses. 
Similar reduction of adiposity have been observed by other authors $(2,19)$. Interestingly, one study reported that the decrease of body weight was caused mainly by the decrease of lean mass, while fat mass remained unaltered during the therapy (20). One may suggest, that differences in physical activity during the therapy might explain observed differences. Observed metabolic and anthropometric changes after the restoration of thyroid function in both hyper- and hypothyroid patients might not be accompanied by normalization of energy expenditure. Levothyroxine-replacement therapy causing decrease of FT3 levels has been proved to be associated with lowering of FT3-dependent resting energy expenditure in contrast to healthy controls (21). Recent systemic review and meta-analysis found that normalization of TSH in levothyroxine-treated patients does not lead to sufficient decrease of low dose lipoprotein and total cholesterol levels (22). These effects might be clinically significant not only for patients primarily treated with levothyroxine because of hypothyroidism, but also for initially hyperthyroid subjects who needed radical therapy with radioiodine or thyroidectomy followed by necessity of levothyroxine substitution. Therefore, prevention of unfavourable anthropometric changes observed during the therapy of thyroid dysfunctions could have beneficial metabolic effects.

Total body adiposity was the major determinant of visfatin concentrations in females with thyroid dysfunctions of autoimmune origin, but jet fat trunk or visceral fat index did not correlate with its concentration. This observation is in line with other studies suggesting that subcutaneous fat tissue contributes well to circulating visfatin level $(23,24)$. Our findings might also explain contradictory results of other studies applying traditional methods for anthropometric assessment (i.e. body mass index, waist-to-hip ratio, or skin fold) $(25,26)$. We have confirmed our previous findings that serum visfatin correlates with TPOAbs in hypothyroid patients, which has been recently also reported in children (27). Likewise, Caixas at al. observed that in hyperthyroid patients fat mass increases during the therapy with concomitant increase of visfatin (9). The design of our study limits our possibilities to conclude whether observed visfatin changes during recovery in hyperthyroid females simply reflect increase of adiposity or is a compensatory response involved in glucose regulation. On the other hand, since TSH receptor is expressed in adipocytes, observed changes might result from TSH receptor stimulation in fat tissue potentially leading to release of visfatin (28). In contrast to other authors, visfatin remained unchanged after recovery in hypothyroid women (9). Visfatin has been suggested to act as a myokine, and in some studies levothyroxine substitution lead to increment of muscle mass (29). We have noticed significant decrease of muscle mass during the therapy, and this difference might explain contradictory results.

The main objective and novelty of our study is the prospective analysis of the link between visfatin, thyroid-related hormones and antithyroid antibodies levels, as well as body composition parameters, including fat content and muscle mass in trunk and limbs. What is more, to the best of our knowledge, this is the first study investigating serum visfatin changes in three different thyrometabolic states in the same individuals. The main limitation of our study is the use of bioimpedance method for body composition analysis, which is not as precise as Dual-energy X-ray absorptiometry (DXA). However, accuracy of bioimpedance has been already proved in several studies, also among patients with thyroid dysfunctions (30). What is more, we applied strict inclusion and exclusion criteria, which allowed us to 
provide more accurate results. Finally, we followed the same patients during the therapy, which limited the influence of individual factors.

\section{Conclusion And Future Perspectives}

We may conclude that restoration of thyroid function is not associated with beneficial changes in body composition, especially among hyperthyroid females, reflected by the significant increase of fat mass followed by the increase of circulating visfatin concentrations. In hypothyroid women, restoration of thyroid function was associated with decrease of fat and muscle masses. All observed alteration of body composition might have negative influence on the eventual energy expenditure in patients after restoration of euthyroidism. This complex interplay between thyroid-related hormones and adipose tissue secreting pro-inflammatory adipocytokines should be considered during the therapy of thyroid dysfunctions. Our findings might be also placed in a broader context of increased long-term cardiovascular risk unrelated to hormonal status in patients with thyroid disorders (31). Based on our results, we could speculate that some additional clinical parameters, such as body weight and fat mass should be incorporated into the current recommended thyroid dysfunction therapy goal along with targeted hormonal values. What is more, it would be valuable to investigate the effect of physical activity on body composition changes during the therapy of severe thyroid dysfunctions in the future interventional, prospective studies on a large group of subjects.

\section{Declarations}

\section{Ethics approval and consent to participate}

The study was approved by the Ethical Committee of Poznan University of Medical Sciences (decision No 351/14) and each participant signed informed written consent.

\section{Consent for publication}

Not applicable

\section{Availability of data and materials}

The datasets used and/or analysed during the current study are available from the corresponding author on reasonable request.

\section{Competing interests}

The authors declare that they have no conflict of interest.

\section{Funding}


This study was partially funded by The National Science Centre in Poland grant nr DEC2012/07/N/NZ5/01736. The study was also supported by Polpharma Scientific Fundation.

\section{Authors' contributions}

NSG conceptualization, funding acquisition, data collection and analysis, writing; AZK data collection and analysis, manuscript review and editing; MK data collection and analysis, manuscript review and editing; ACz data collection and analysis, manuscript review and editing; PZ data collection and analysis, manuscript review and editing; DMW data collection and analysis, manuscript review and editing; JS data collection and analysis, manuscript review and editing; MR data collection and

analysis, manuscript review and editing, supervision.

\section{Acknowledgement}

Not applicable

\section{References}

1. Choe SS, Huh JY, Hwang IJ, Kim JI, Kim JB. Adipose tissue remodeling: its role in energy metabolism and metabolic disorders. Front Endocrinol. 2016;7:30.

2. Stangierski A, Ruchała M, Krauze T, Moczko J, Guzik P. Treatment of severe thyroid function disorders and changes in body composition. Endokrynologia Polska. 2016;67(4):359-66.

3. Jacobsen R, Lundsgaard C, Lorenzen J, Toubro S, Perrild H, Krog-Mikkelsen I, et al. Subnormal energy expenditure: a putative causal factor in the weight gain induced by treatment of hyperthyroidism. Diabetes Obesity Metabolism. 2006;8(2):220-7.

4. Owecki M, Sawicka-Gutaj N, Owecki M, Ambrosius W, Dorszewska J, Oczkowska A, et al. Pulsatility Index in Carotid Arteries is Increased in Levothyroxine-Treated Hashimoto Disease. Horm Metab Res. 2015;47(08):577-80.

5. Carbotta G, Tartaglia F, Giuliani A, Carbotta S, Tromba L, Jacomelli I, et al. Cardiovascular risk in chronic autoimmune thyroiditis and subclinical hypothyroidism patients. A cluster analysis. Int $\mathrm{J}$ Cardiol. 2017;230:115-9.

6. Sawicka-Gutaj N, Waligórska-Stachura J, Andrusiewicz M, Biczysko M, Sowiński J, Skrobisz J, et al. Nicotinamide phosphorybosiltransferase overexpression in thyroid malignancies and its correlation with tumor stage and with survivin/survivin DEx3 expression. Tumor Biology. 2015;36(10):7859-63.

7. Sawicka-Gutaj N, Andrusiewicz M, Czarnywojtek A, Waligórska-Stachura J, Biczysko M, Skrobisz J, et al. Changes of Nicotinamide Phosphoribosyltransferase Expressions in Thyroid Glands of Patients with Different Thyroid Pathologies. BioMed research international. 2018;2018.

8. Sawicka-Gutaj N, Budny B, Zybek-Kocik A, Sowiński J, Ziemnicka K, Waligórska-Stachura J, et al. Nicotinamide phosphoribosyltransferase leukocyte overexpression in Graves' opthalmopathy. Endocrine. 2016;53(2):497-504. 
9. Caixàs A, Tirado R, Vendrell J, Gallart L, Megía A, Simón I, et al. Plasma visfatin concentrations increase in both hyper and hypothyroid subjects after normalization of thyroid function and are not related to insulin resistance, anthropometric or inflammatory parameters. Clin Endocrinol. 2009;71(5):733-8.

10. Chu C-H, Lee J-K, Wang M-C, Lu C-C, Sun C-C, Chuang M-J, et al. Change of visfatin, C-reactive protein concentrations, and insulin sensitivity in patients with hyperthyroidism. Metabolism. 2008;57(10):1380-3.

11. Ozkaya M, Sahin M, Cakal E, Yuzbasioglu F, Sezer K, Kilinc M, et al. Visfatin plasma concentrations in patients with hyperthyroidism and hypothyroidism before and after control of thyroid function. $J$ Endocrinol Investig. 2009;32(5):435-9.

12. Han J, Zhang T, Xiao W, Chang C, Ai H. Up-regulation of visfatin expression in subjects with hyperthyroidism and hypothyroidism is partially relevant to a nonlinear regulation mechanism between visfatin and tri-iodothyronine with various concentrations. Chin Med J. 2012;125(5):87481.

13. Yildiz U, Bukan N, Aktas B, Toruner F. The relationship between thyroid function and serum levels of angiopoietin-like protein 3 , leptin and visfatin. ACTA ENDOCRINOLOGICA-BUCHAREST. 2013;9(2):171-9.

14. Sawicka-Gutaj N, Zybek-Kocik A, Kloska M, Czarnywojtek A, Sowiński J, Budny B, et al. Determinants of Visfatin/NAMPT Serum Concentration and its Leukocyte Expression in Hyperthyroidism. Horm Metab Res. 2018;50(09):653-60.

15. Sawicka-Gutaj N, Zybek-Kocik A, Klimowicz A, Kloska M, Mańkowska-Wierzbicka D, Sowiński J, et al. Circulating visfatin in hypothyroidism is associated with free thyroid hormones and antithyroperoxidase antibodies. International journal of endocrinology. 2016;2016.

16. Brennan MD, Powell C, Kaufman KR, Sun PC, Bahn RS, Nair KS. The impact of overt and subclinical hyperthyroidism on skeletal muscle. Thyroid. 2006;16(4):375-80.

17. Brennan MD, Coenen-Schimke JM, Bigelow ML, Nair KS. Changes in skeletal muscle protein metabolism and myosin heavy chain isoform messenger ribonucleic acid abundance after treatment of hyperthyroidism. The Journal of Clinical Endocrinology Metabolism. 2006;91(11):4650-6.

18. Chng C-L, Lim AYY, Tan HC, Kovalik J-P, Tham KW, Bee YM, et al. Physiological and metabolic changes during the transition from hyperthyroidism to euthyroidism in Graves' disease. Thyroid. 2016;26(10):1422-30.

19. Sánchez A, Carretto H, Ulla MR, Capozza R. Body composition of patients with primary hypothyroidism evaluated by dual-energy $\mathrm{X}$-ray absorptiometry and its changes after treatment with levo-thyroxine. The Endocrinologist. 2004;14(6):321-7.

20. Karmisholt J, Andersen S, Laurberg P. Weight loss after therapy of hypothyroidism is mainly caused by excretion of excess body water associated with myxoedema. The Journal of Clinical Endocrinology Metabolism. 2011;96(1):E99-103. 
21. Samuels MH, Kolobova I, Smeraglio A, Peters D, Purnell JQ, Schuff KG. Effects of levothyroxine replacement or suppressive therapy on energy expenditure and body composition. Thyroid. 2016;26(3):347-55.

22. McAninch EA, Rajan KB, Miller CH, Bianco AC. Systemic Thyroid Hormone Status During Levothyroxine Therapy In Hypothyroidism: A Systematic Review and Meta-Analysis. The Journal of Clinical Endocrinology \& Metabolism.

23. Berndt J, Klöting N, Kralisch S, Kovacs P, Fasshauer M, Schön MR, et al. Plasma visfatin concentrations and fat depot-specific mRNA expression in humans. Diabetes. 2005;54(10):2911-6.

24. KLIMONTOV V, BULUMBAEVA D, BGATOVA NP, TASKAEVA I, FAZULLINA O, ORLOV N, et al. The Relationships between Serum Levels of Adipokines, Body Fat Distribution, and Subcutaneous Microvasculature in Type 2 Diabetic Subjects. Am Diabetes Assoc; 2018.

25. Willers SM, Brunekreef B, Abrahamse-Berkeveld M, Van De Heijning B, Van Der Beek E, Postma DS, et al. Serum visfatin and leptin in relation to childhood adiposity and body fat distribution: the PIAMA birth cohort study. Annals of nutrition metabolism. 2015;66(2-3):63-71.

26. Dogru T, Sonmez A, Tasci I, Bozoglu E, Yilmaz MI, Genc H, et al. Plasma visfatin levels in patients with newly diagnosed and untreated type 2 diabetes mellitus and impaired glucose tolerance. Diabetes Res Clin Pract. 2007;76(1):24-9.

27. Farghaly HS, Metwalley KA, Ahmed F-A, Raafat DM, El-Asheer O, Ali AM, et al. Visfatin level in children and adolescents with autoimmune thyroiditis. Therapeutic advances in endocrinology metabolism. 2017;8(8):119-25.

28. Briet C, Suteau-Courant V, Munier M, Rodien P. Thyrotropin receptor, still much to be learned from the patients. Best Practice \& Research Clinical Endocrinology \& Metabolism. 2018.

29. Krzysik-Walker SM, Ocón-Grove OM, Maddineni SR, Hendricks GL III, Ramachandran R. Is visfatin an adipokine or myokine? Evidence for greater visfatin expression in skeletal muscle than visceral fat in chickens. Endocrinology. 2007;149(4):1543-50.

30. Sartorio A, Ferrero S, Trecate L, Bedogni G. Thyroid function is more strongly associated with body impedance than anthropometry in healthy subjects. J Endocrinol Investig. 2002;25(7):620-3.

31. Nyirenda MJ, Clark DN, Finlayson AR, Read J, Elders A, Bain M, et al. Thyroid disease and increased cardiovascular risk. Thyroid. 2005;15(7):718-24.

\section{Figures}


a)

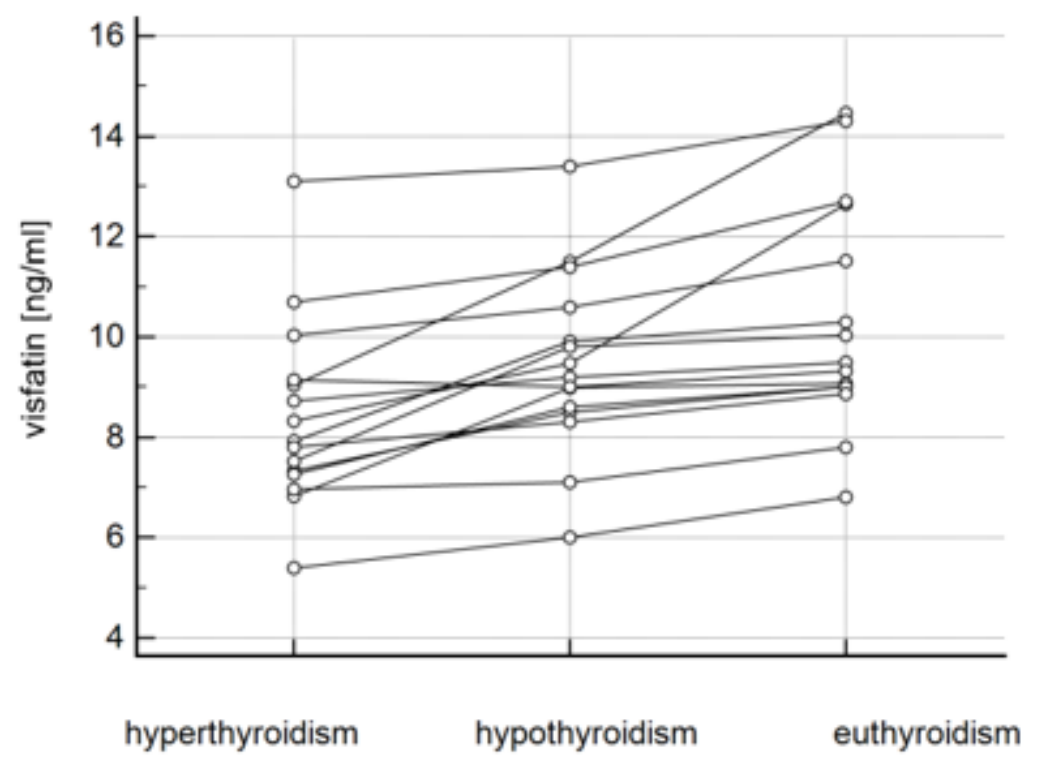

b)

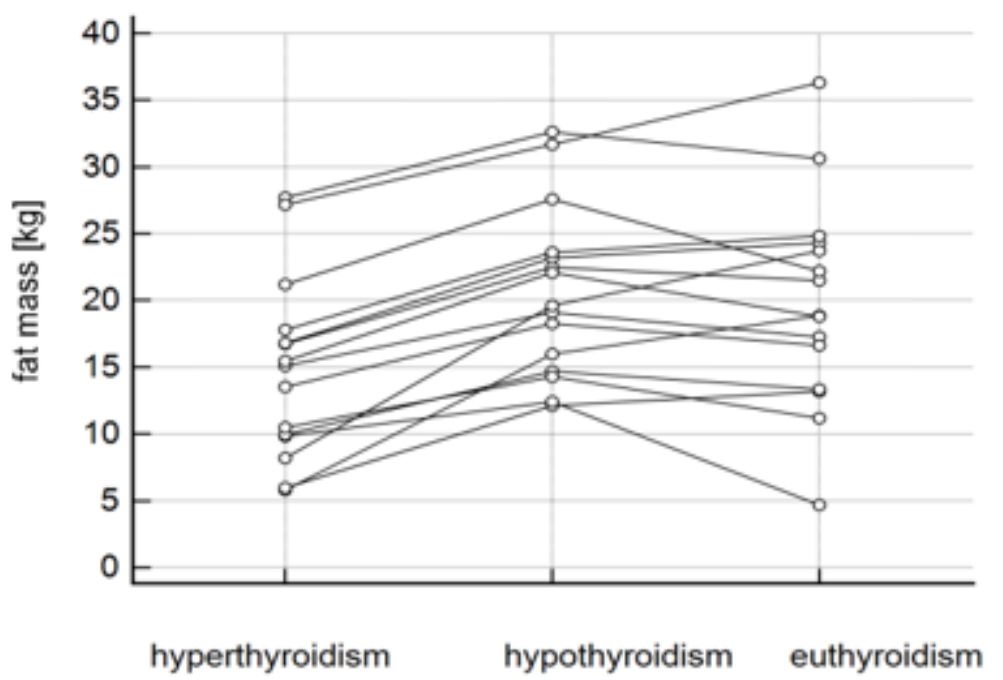

Figure 1

Individual visfatin (a) and fat mass (b) changes in each patient evaluated in hyperthyroidism, hypothyroidism, and euthyrodism. 